\title{
Pesquisa de clima organizacional como impacto na motivação das gerações $\mathrm{X}$ e $\mathrm{Y}$
}

\author{
Organizational climate survey as impact on motivation of generations $\mathrm{X}$ e $\mathrm{Y}$
}

Jesimar da Cruz Alves ${ }^{1}$, Claudenir Pereira do Val ${ }^{2}$, Rosimere Lavinas Feijó ${ }^{3}$.

\begin{abstract}
Resumo
Este estudo teve como objetivo principal demonstrar a maneira pela qual a pesquisa de clima organizacional pode impactar os processos motivacionais das gerações X e Y. Nesse sentido, primou-se por analisar os principais fatores que estas gerações consideram como instrumentos motivacionais, e consequentemente, apontar os mecanismos de implementação de uma pesquisa de clima que apresentasse resultados eficazes. Para tanto, foi utilizada como metodologia uma pesquisa bibliográfica através dos principais autores, e para melhor compreensão, foi realizado também um estudo de campo, de caráter exploratório. Pudemos concluir, ao final do estudo, que as gerações $\mathrm{X}$ e Y sofrem impactos motivacionais diferentes, e que a pesquisa de clima é um forte instrumento de percepção dos fatores motivacionais, devendo dessa maneira, ter maior aplicabilidade na gestão das organizações modernas. Palavras-Chave: Pesquisa de Clima. Motivação. Geração X e Y.
\end{abstract}

Como citar esse artigo. Alvez JC, Val CP, Feijó RL. Pesquisa de clima organizacional como impacto na motivação das gerações X e Y. Revista Mosaico. 2015 Jul./Dez.; 06 (2): 41-47.

\begin{abstract}
This study aimed to demonstrate the way in which the organizational climate survey may impact the motivational processes of generations $\mathrm{X}$ and $\mathrm{Y}$. In this sense, excelled by analyzing the main factors these generations see as motivational tools, and consequently point implementation mechanisms of climate research to produce effective results. Thus, it was used as a literature search methodology through the main authors, and for better understanding, was also carried out a field study, exploratory. We concluded at the end of the study, the X and Y generations suffer different motivational impacts, and that the climate survey is a strong tool of perception of the motivational factors and should thus have wider applicability in the management of modern organizations. Keywords: Climate Survey. Motivation. Generation X and Y.
\end{abstract}

\section{Introdução}

A motivação profissional é alimentada pelas ações internas e externas, são meios que determinam a satisfação pessoal dos colaboradores. Não existe como motivar pessoas com ações internas, pois estes fatores são pessoais e de crivo íntimo. As gerações $X$ e Y têm características diferentes de gerenciamento, pois suas experiências motivacionais são alimentadas por fatores diferentes, devido às experiências pessoais e por situações diversas que foram discutidas neste estudo. O clima organizacional é considerado como um nivelador de satisfação dos colaboradores, mensurando as vertentes psicológicas, estruturais e externas dos mesmos, como objetivo de identificar os reais gaps que necessitam de alinhamento para que o corpo funcional esteja motivado e determinado a buscar novos desafios estratégicos. A pesquisa de clima é um instrumento que propicia a organização identificar estes desvios e propor caminhos de melhoria nos planejamentos estratégicos das organizações, determinando meios e mecanismos que os níveis estratégicos devem perseguir. Mas quando não alinhada de forma correta, pode causar desvios de informação e derrubar os projetos levando as organizações a desperdiçarem recursos financeiros e seu tempo debruçado em situações desnecessárias. O objetivo deste estudo foi de analisar como as ações da pesquisa de clima podem influenciar nos fatores motivacionais das gerações $\mathrm{X}$ e Y buscando identificar mecanismos que devem ser adotados com cada geração.

\section{Motivação}

Diante das frequentes ferramentas de gestão de pessoas existentes nas organizações modernas, é notável que os gestores busquem mecanismos que façam com que seus colaboradores desempenhem suas atividades de forma satisfatória e motivada. Segundo Archer $(1989$, p. 25), [...] a motivação, portanto, nasce somente

1. Universidade Severino Sombra, Professor do Curso Superior em Administração, Pedagogia e Engenharia de Produção.

2. Universidade Severino Sombra, Coordenadora da CPA-USS; Professora Assistente II do Curso Superior em Administração.

3. Universidade Severino Sombra, Curso de Administração. 
das necessidades humanas e não daquelas coisas que satisfazem estas necessidades. Na visão do autor, é possível compreender que os fatores motivacionais estabelecem satisfações não somente internas, pois os seres humanos carecem de mecanismos externos para buscarem sua motivação. Analisando as gerações X e $\mathrm{Y}$, é possível perceber que estes fatores motivacionais externos podem ser diferenciados, pois o que satisfaz um sujeito podem não ser o mesmo que vai satisfazer o outro, proporcionando assim, ações diferenciadas de motivação. Ainda Archer (citado por BERGAMINI e CODA, 1989, p. 24) destaca cinco interpretações errôneas:

1. A crença de que uma pessoa possa literalmente motivar outra;

2. A crença de que a pessoa é motivada como resultado da satisfação;

3. A crença de que aquilo que motiva o comportamento seja também aquilo que determina sua direção, tanto positiva como negativamente;

4. A crença de que a motivação seja o catalisador que induz a comportamentos positivos;

5. A crença de que fatores de motivação e fatores de satisfação sejam a mesma coisa.

De acordo com o observado na discussão de Archer, a maioria das organizações erra em seu processo motivacional por acreditar primeiramente que elas possuem o poder de motivar pessoas. Ainda pode-se observar que um dos fatores que levam a falha no processo motivacional é acreditar que a satisfação pode ser considerada como motivação; este processo é errôneo devido ao fato de que o que satisfaz a um colaborador não vai satisfazer o outro, o que sugere que a satisfação não pode ser considerada como padrão motivacional. Ainda apresenta a falha de se considerar que o comportamento e a direção sempre serão influenciados positivamente mediante a motivação; e não é bem assim, pois as pessoas não agem positiva ou negativamente só pela motivação, outros fatores influenciam essa ação. Para as gerações X e Y esta visão contribui para o aspecto de se observar que as gerações recebem motivações diferenciadas devido a culturas diferentes. É significativo perceber que a motivação está apoiada nas necessidades e não somente nelas, mas também no sentimento de gostar do que se faz.

Segundo Bernardinho (2006, p. 115 e 116),

[...] a motivação baseia-se em dois pilares: o primeiro deles é a necessidade. Se você precisa, vai correr atrás e se dedicar. $\mathrm{O}$ segundo é a paixão. Se você gosta, ama o que faz, vai querer melhorar sempre.

Nota-se então que a motivação está baseada na necessidade e na paixão, pois acredita que se a pessoa precisa ela vai buscar e se dedicar de todas as formas para conseguir, e amando o que faz desperta a vontade de fazer sempre o melhor, pois se a pessoa gosta do que faz tende a executar de forma satisfatória e motivada. Nas gerações X e Y essa visão não pode ser considerada como regra, pois cada geração apresenta necessidades diferentes e o sentimento pelo que faz também se mostra diferente. Em tudo o que se faz é preciso ter uma força, uma sensação positiva para levar a uma realização que nasce dentro de cada indivíduo. Segundo Vergas (citado por FIORELLI, 2004, p. 118) motivação é uma força, uma energia que nos impulsiona na direção de alguma coisa que nasce de nossas necessidades interiores. É possível compreender que cada indivíduo é motivado por uma força, um vigor, que proporciona buscar aquilo que é preciso para satisfazer as necessidades interiores de cada pessoa. Este aspecto é observado nas gerações $\mathrm{X}$ e $\mathrm{Y}$ identificando que cada uma apresenta uma disposição, um empenho diferente para satisfazer essas necessidades interiores, pois a força que motiva uma não é a mesma que motiva a outra, fazendo com que cada uma aja da forma como se sinta mais motivada para a satisfação dessas necessidades. Desta forma, fica claro que para atingir um objetivo é preciso estar motivado para que a energia e disposição de cada pessoa estejam no seu mais alto grau.

Robbins (2002, p. 151) define motivação [...] como o processo responsável pela intensidade, direção e persistência dos esforços de uma pessoa para o alcance de uma determinada meta. Compreende-se então que a motivação seja capaz de definir com que grau de vontade a pessoa está para alcançar suas metas, pois a motivação é considerada responsável por esse processo. Com relação às gerações $\mathrm{X} \mathrm{e} \mathrm{Y} \mathrm{pode-se} \mathrm{perceber} \mathrm{que} \mathrm{a}$ vontade de alcançar suas metas é distinta, tendo em vista que o que desperta vontade em uma, não desperta na outra, e que a intensidade que uma tem para se dedicar nessa busca é diferente da outra; contudo, as metas podem ser alcançadas cada uma a sua maneira. Fica claro que o empenho que as pessoas têm para buscar algo pode ser conduzido pela motivação. De acordo com Chiavenato $(1994$, p. 165) [...] a motivação pode ser conceituada como o esforço e tenacidade exercidos pela pessoa para fazer algo ou alcançar algo. Baseado na citação de Chiavenato é possível notar que a motivação pode surgir da dedicação e persistência que a pessoa tem para alcançar suas metas e objetivos; vem da forma com que as pessoas se empenham para alcançar aquilo que querem. É possível perceber que as gerações X e Y buscam alcançar seus objetivos; mesmo tendo cada uma sua particularidade despendem esforços para alcançar algo ou buscar algo.

\section{Clima Organizacional}

Devido às frequentes mudanças que vem ocorrendo nas relações comerciais torna-se necessário 
que sejam observadas e analisadas principalmente as mudanças internas que ocorrem na organização e que podem ser identificadas através das atitudes dos colaboradores.

Martins (2008, p.29) diz que:

[...] Devido às rápidas mudanças que vem ocorrendo nos anos de globalização, as empresas têm tentado conhecer melhor a dinâmica da vida organizacional, buscando identificar como trabalhadores expostos a uma série de estímulos oriundos da organização e do ambiente de trabalho têm percepções similares e atribuem significados semelhantes aos aspectos importantes da vida organizacional.

De acordo com o autor é possível compreender que a globalização tem obrigado as organizações a se conhecer melhor, pois elas precisam saber como é o funcionamento de todas as áreas da organização, como os trabalhadores reagem aos estímulos recebidos e o que valorizam dentro da organização, para que sejam feitas adequações que possibilitem que seja um ambiente em que as pessoas tenham prazer de estar e de fazer parte. É notável que as gerações $\mathrm{X}$ e Y têm suas diferenças, porém o autor nos mostra que os trabalhadores em geral dentro da organização têm suas percepções similares e atribuem significados semelhantes ao que consideram importante na vida da organização, mas vale ressaltar que cada uma identifica da sua maneira e pode até ser similar ou semelhante, mas nunca igual devido às características de cada uma. O clima pode ser identificado dentro da organização através da conduta e da forma como os colaboradores se comportam. Campello e Oliveira (2008, p. 3) dizem que a palavra clima originase do grego klimae e significa tendência ou inclinação. O clima é algo que não se pode ver ou tocar, mas ele é facilmente percebido dentro de uma organização através do comportamento dos seus colaboradores. Nesse caso, a visão dos autores leva a compreender que o clima pode ser percebido pela maneira como os colaboradores agem dentro da organização, através da conduta e da forma como desempenham seu papel. Para as gerações $\mathrm{X}$ e Y essa percepção do clima deve ocorrer de forma que não se generalize os resultados verificados, pois cada uma se comporta dentro da organização de maneira diferente, para tanto é necessária uma avaliação do comportamento de ambas as gerações para se chegar a uma conclusão. Entende-se que o clima organizacional revela que o ambiente pode influenciar a motivação, é através dele que se busca criar um ambiente mais agradável às pessoas envolvidas, contribuindo para a melhoria do comprometimento e da qualidade, aumento da produtividade, melhoria da comunicação, provocando o bom comportamento das pessoas dentro do ambiente de trabalho.

Para Chiavenato (2000, p. 413):

[...] O conceito de clima representa o quadro mais amplo da influência ambiental sobre a motivação. O clima organizacional é responsável por criar um ambiente que propicie a satisfação ou insatisfação entre os envolvidos. É a partir da análise do clima organizacional interno que se identifica a relação existente entre os colaboradores e empresa.

Desta forma, fica claro então que o clima tem total influência no ambiente organizacional impactando diretamente na motivação dos colaboradores.

Ainda Chiavenato (2006, p. 273) diz que:

[...] Clima Organizacional constitui o meio interno de uma organização, a atmosfera psicológica e característica que existe em cada organização. O clima organizacional é o ambiente humano dentro do qual as pessoas de uma organização fazem o seu trabalho. Constitui a qualidade ou propriedade do ambiente organizacional que é percebida ou experimentada pelos participantes da empresa e que influencia o seu comportamento.

Diante da visão de Chiavenato, é possível compreender que o clima organizacional compreende o ambiente e as pessoas que nele estão inseridas; diante disso, é notável que as pessoas precisem de um ambiente agradável e propício para desenvolver suas atividades com satisfação e qualidade. Se o clima for ruim, o ambiente não apresentar uma boa estrutura, as pessoas irão se desmotivar, podem surgir conflitos internos, a produção vai cair, a qualidade não será a mesma, a comunicação será abalada e com isso a imagem da organização também vai se abalar. Para tanto é necessário que se faça um contínuo acompanhamento do clima organizacional para que não aconteça tarde demais e comprometa a imagem da organização. Perante as diferenças existentes entre as gerações $\mathrm{X}$ e $\mathrm{Y}$, fica claro que estabelecer um clima organizacional que seja agradável a ambas é um tanto quanto difícil, pois o que influencia a satisfação, motivação e estimula no ambiente de trabalho não é o que influencia a outra, ou talvez não da mesma maneira, devido à particularidade existente entre elas. A partir de um elevado clima organizacional é notável a alteração no ambiente; com isso as pessoas envolvidas se motivam a se comprometer com os interesses da organização, por se sentirem importantes em fazer parte dela e partilhar dos mesmos objetivos, independentemente do nível que ocupam na organização.

\section{Pesquisa de Clima Organizacional}

A pesquisa de Clima Organizacional tem como objetivo, em qualquer empresa, melhorar a relação colaborador $\mathrm{x}$ organização, garantindo condições de trabalho adequadas em um ambiente adequado, proporcionando oportunidades de crescimento e desenvolvimento que permitam ao colaborador se sentir bem e valorizado. A pesquisa também verifica com está o ambiente externo e interno da organização, a motivação 
dos colaboradores e o que precisa ser corrigido na administração e na estrutura da organização. Estudos de clima são particularmente úteis, porque fornecem um diagnóstico geral da empresa, bem como indicações de áreas carentes de uma atenção especial (SOUZA, 1982, p.14). Diante disso pode-se dizer que a pesquisa de clima contribui para a eficácia organizacional, pois através dela que é identificado o clima ruim e porque, a partir daí podem ser adotadas medidas para melhorá-lo. Para as gerações $\mathrm{X}$ e $\mathrm{Y}$ a pesquisa de clima organizacional tem uma importância especial, pois ao participarem de uma pesquisa de clima elas anseiam que seja mudado aquilo que incomoda, visto que a pesquisa de clima tem o objetivo de identificar onde e por que o clima está ruim, para que seja traçado um plano de ação corretivo. A pesquisa de clima pode ser considerada como um instrumento para investigação da realidade da organização, pois identifica e revela o que os colaboradores acham que pode estar ocorrendo na organização em determinado momento. Mediante a visão do autor nota-se que o objetivo da pesquisa de clima organizacional é tornar claro o que organização e colaboradores sentem e percebem no ambiente em que estão inseridos que, caso detectem alguma inconformidade que possa influenciar de maneira negativa o nível de satisfação e motivação no ambiente organizacional, ela é o instrumento que as organizações possuem para identificar à medida que conta com a participação de pessoas diferentes, de gerações diferentes. Percebe-se então que as gerações $\mathrm{X}$ e Y, assim como a organização, apresentam inconformidades que precisam ser detectadas o mais rápido possível, para que sejam solucionadas o quanto antes e permitam a administração efetuar as devidas mudanças na busca pelo desenvolvimento e eficácia organizacional. A pesquisa de clima organizacional tem uma grande importância na gestão dos recursos humanos, pois é considerada uma ferramenta segura e objetiva que identifica os aspectos positivos e negativos que precisam ser mudados para melhoria do clima organizacional, que proporcionará a organização o aumento da qualidade e da produtividade e superação dos resultados.

Luz afirma sobre a necessidade da pesquisa de Clima Organizacional que:

As empresas devem ouvir seus colaboradores através da área de RH porque faz parte de sua missão proporciona-lhes um bom clima organizacional. O compromisso de tornar a mão-de-obra satisfeita ou 'motivada' está contido tanto na literatura técnica quanto ao cotidiano da Administração de Recursos Humanos. Logo, se 'motivar' ou ao menos tornar satisfeitos os funcionários é parte da missão de ARH, então ela tem o dever de diagnosticar, periodicamente, o clima organizacional, com o objetivo de saber se está sendo cumprindo sua missão. (LUZ, 2003, p. 22)
De acordo com o observado na visão do autor, a Administração de Recursos Humanos tem como função motivar ou ao menos tornar satisfeitos os colaboradores da organização; logo, para identificar o nível de satisfação e motivação dos colaboradores é necessário aplicar a pesquisa de clima, ferramenta eficiente e eficaz disponível para tornar os programas da Administração de Recursos Humanos mais efetivos, mediante a realidade do ambiente organizacional evidenciada através da pesquisa. Fica claro que as gerações $\mathrm{X}$ e $\mathrm{Y}$ se motivam e se satisfazem de formas diferentes e cabe a Administração de Recursos Humanos verificar como isso acontece dentro da organização; para tanto, é importante utilizar a pesquisa de clima para esse diagnóstico como forma de identificar a realidade do ambiente e implantar as mudanças necessárias para tornar o ambiente organizacional adequado, satisfatório e motivador aos colaboradores, de acordo com sua missão.

Diante dos estudos acerca da pesquisa de clima, verifica-se que a organização pode ser considerada a responsável poruma equipe satisfeita e mais participativa. Brum (1998, p.28) esclarece que, para se ter uma equipe satisfeita e com atuação mais participativa, fazse necessário algumas ações por parte da organização, como o emprego de medidas, fundamentadas na pesquisa de clima organizacional como ferramenta para alcançar os objetivos da organização. Na visão do autor, a organização é a responsável pela satisfação da equipe e sua melhor atuação, a partir da aplicação de medidas que são evidenciadas na pesquisa de clima com o objetivo de alcançar e superar os objetivos determinados. Percebese nas gerações $\mathrm{X}$ e $\mathrm{Y}$ que existe uma necessidade de aplicação dessas medidas identificadas e relatadas pela pesquisa de clima como fator motivacional, levando em conta suas diferentes características, para que sejam adotadas medidas que satisfaçam cada uma e também a organização, pois todos os envolvidos precisam estar satisfeitos e motivados para alcançar e superar os objetivos propostos. O colaborador espera que ao participar de uma pesquisa de clima ele possa ser visto com mais importância pela organização e anseia por mudanças em função do diagnóstico obtido a partir de suas respostas.

\section{Gerações X e Geração Y}

Twenge (2010 citado por Santos 2011, p.45) acredita que as gerações não podem ser tratadas como agrupamentos separados de pessoas, mas sim como fruto de uma mudança social que ocorre gradualmente com o passar do tempo. Para o autor, as organizações atualmente precisam olhar para as gerações como grupo, tendo em vista que as gerações são consequências das mudanças que vem ocorrendo na sociedade e 
que precisam interagir para atingir seus objetivos, pois individualmente pode não surtir o mesmo efeito; atuando em grupo eles se auxiliam na busca da eficácia organizacional. É importante avaliar esse conceito de grupo que o autor mostra, principalmente quando se trata de duas gerações com características distintas, para que funcione na teoria e na prática; mas é valido lembrar que para que isso ocorra é preciso que a liderança seja capaz de lidar com tal situação e motivar a todos a agirem em grupo, sem conflito e sempre motivados, de modo que não afete os resultados. Devido à velocidade com que as organizações precisam se ajustar ao mercado atualmente, elas devem incentivar a possibilidade de colaboração e integração entre as gerações $\mathrm{X}$ e Y, devido a relação aprende $\mathrm{x}$ ensina que pode existir entre elas; é notável que essa barganha de conhecimento e experiência seja benéfica tanto ao colaborador quanto à organização em tempos de concorrência acirrada. Oliveira (2010, p. 60) mostra que é no relacionamento entre as gerações que está a chave para o resgate do equilíbrio necessário para estes novos tempos. De acordo com o autor, compreende-se que as características distintas e experiências particulares das gerações $\mathrm{X}$ e $\mathrm{Y}$, podem ser somadas umas as outras, refinadas e aperfeiçoadas diante das diferentes situações que possam ocorrer na organização de forma que contribui para o aprimoramento profissional e crescimento dos colaboradores e também da organização. É importante destacar que apesar de o mercado exigir que as gerações $\mathrm{X}$ e $\mathrm{Y}$ se tornem um só grupo dentro das organizações, ele não exige que troquem suas raízes, pois cada geração apresenta suas particularidades e seus valores e, portanto, apesar da boa convivência ser necessária em tempos de globalização, a cultura arraigada, os paradigmas e os conceitos estão marcados em cada um, e pode gerar certo conflito no ambiente em que estão inseridos, pois não deixam de ser da geração $\mathrm{X}$ e da geração $\mathrm{Y}$.

\section{Materiais e Métodos}

A metodologia utilizada foi a pesquisa bibliográfica analítica através dos principais autores que norteiam os temas em questão, e como bibliografias complementares foram utilizadas pesquisas em artigos, jornais, revistas entre outras fontes que contribuíram para construção da revisão de literatura do estudo. Para melhor compreensão, foi realizado um estudo exploratório de campo através da utilização de um questionário investigativo composto de 6 (seis) perguntas fechadas, sendo 2 (duas) de caráter investigativo demográfico e 4 (quatro) de caráter analítico, que foram direcionadas a uma amostra de 172 profissionais sendo 86 da geração $\mathrm{X}$ (mais de 35 anos), e 86 profissionais da geração $\mathrm{Y}$ (até 35 anos), com o objetivo de compreender como os mesmos interpretam a eficácia da pesquisa de clima, e quais fatores buscam satisfazer os meios motivacionais de cada geração. A pesquisa de campo foi realizada no município de Vassouras/RJ no período de abril a maio de 2015, com profissionais de empresas diversas, onde os pesquisados foram abordados fora do ambiente de trabalho com o objetivo de aplicar o questionário em um clima favorável e propício às respostas, buscando uma maior proximidade das respostas obtidas com a veracidade dos fatos.

\section{Resultados e Discussão}

Após a realização da pesquisa e comparando-se os resultados das entrevistas, verificou-se que para os profissionais da geração X como mostra o gráfico 1 , o fator mais importante para motivação é o salário com $37 \%$, acompanhado pelo ambiente de trabalho com $14 \%$ e em seguida a valorização profissional com 13\%. Para a geração Y representada no gráfico 2, o fator mais importante para motivação é a valorização profissional com $30 \%$, seguido por salário com $19 \%$ e desafios da função com $16 \%$. Esta comparação foi satisfatória para a pesquisa em questão, pois percebe-se que devido a geração $\mathrm{X}$ ser composta por pessoas com idade aproximada de 40 anos eles consideram o salário como maior fonte de motivação, mesmo sabendo que é por pouco tempo, tendo em vista que após um período as pessoas comprometem toda a quantia e se desmotivam até a próxima alteração salarial, por não terem a mesma disposição para mudanças como ocorre na geração $\mathrm{Y}$, considerada a geração da internet e dos avanços tecnológicos, que é motivada pela valorização do trabalho e não aceita ficar estagnada, gosta de mudanças e desafios.

Gráfico 1. Fatores importantes para motivação dos entrevistados da Geração X

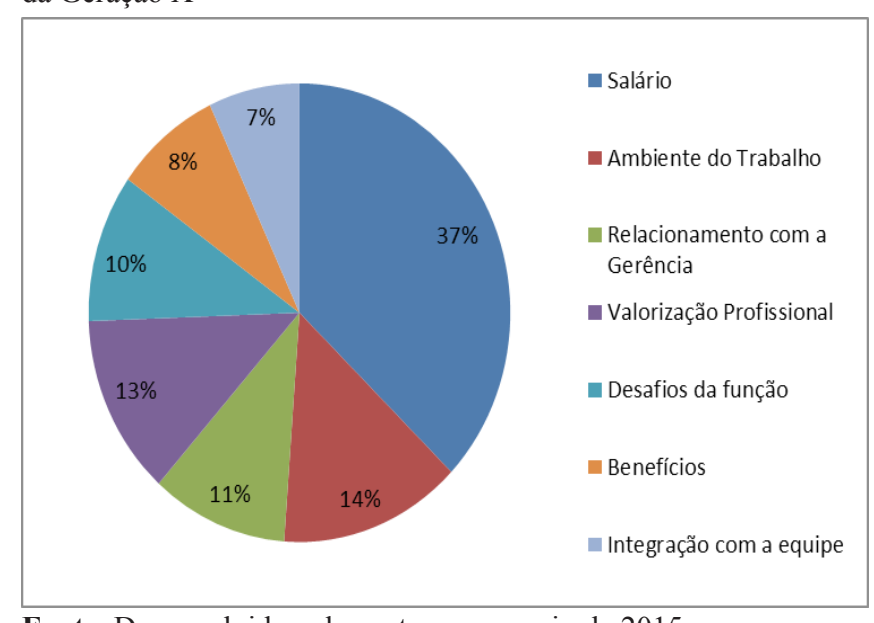

Fonte. Desenvolvido pelos autores em maio de 2015 
Gráfico 2. Fatores importantes para motivação dos entrevistados da Geração Y

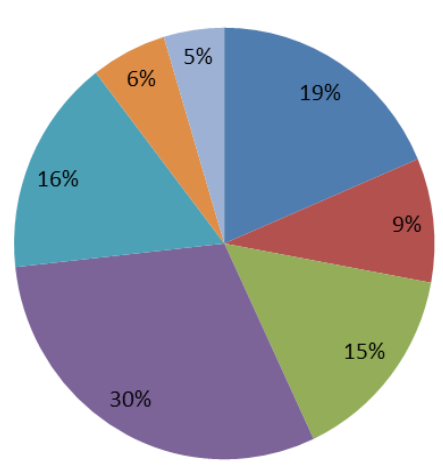

- Salário

Ambiente do Trabalho

- Relacionamento com a Gerência

- Valorização Profissional

- Desafios da função

- Benefícios

- Integração com a equipe

Fonte. Desenvolvido pelos autores em maio de 2015

\section{Sugestões de Aplicação da Pesquisa de Clima}

As gerações $\mathrm{X}$ e $\mathrm{Y}$ não se comportam da mesma forma. A geração $\mathrm{X}$, formada em sua maioria por homens, é uma geração conservadora e experiente que tem muito a ensinar aos jovens da geração Y, e também a aprender com eles; esses profissionais não gostam de mudanças e valorizam a família; a geração Y é a dos jovens inovadores que utilizam a tecnologia a seu favor, e levam esse conhecimento para dentro das organizações. A motivação também não é vista de forma igual; verificou-se que o salário é o fator que mais motiva na geração $\mathrm{X}$, onde acreditase que a motivação é sempre motivada pela empresa, e na geração $\mathrm{Y}$ foi a valorização profissional; para os jovens da geração Y é mais importante ser valorizado profissionalmente do que ter apenas salário, para eles se motivar depende de fatores externos. A pesquisa de clima ajuda dentro das organizações quando é dado o feedback aos participantes. Caso isso não ocorra, os colaboradores ficam frustrados e desmotivados; isso pode ser percebido principalmente na geração $\mathrm{X}$ que participa frequentemente de pesquisas de clima e não percebe mudanças; as gerações esperam que a pesquisa de clima seja um instrumento de comunicação entre colaboradores e organização. Sugere-se para as organizações a utilização do fluxograma abaixo (figura 1) para aplicação da pesquisa de clima a partir do momento em que todos compreendem a importância da mesma, pois através dele pode-se facilitar a apuração dos resultados e o desenvolvimento do plano de ação que será implantado.

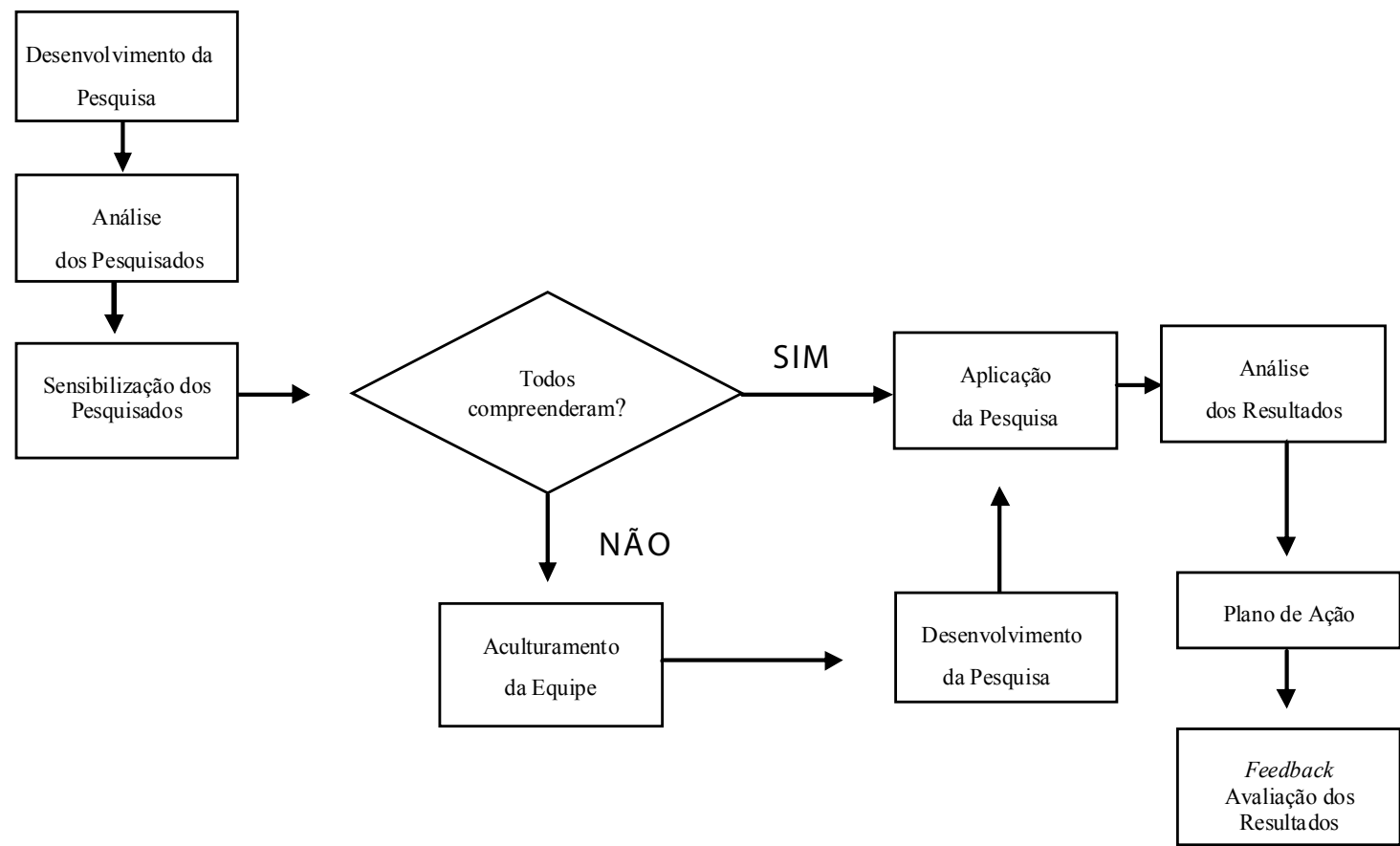

Figura 1. Fluxograma para aplicação da Pesquisa de Clima Fonte: Desenvolvido pelos autores em maio 2015 


\section{Conclusão}

Podemos concluir que o objetivo deste estudo foi completamente respondido uma vez que ficou claro que as gerações $\mathrm{X}$ e $\mathrm{Y}$ se comportam de forma diferente frente à aplicação da pesquisa de clima, e seus fatores motivacionais são, de certa forma, atendidos de acordo com critérios diferenciados. A geração $\mathrm{X}$ é mais conservadora que a geração $\mathrm{Y}$, aceita as mudanças, mas não são favoráveis, porém quando elas ocorrem, procuram se ajustar, pois já possuem experiência suficiente no mercado de trabalho e sabem como as mudanças são importantes; gostam de flexibilidade, e não gostam de supervisão, pois acreditam que após delegadas às tarefas, não precisa de ninguém para conferir como estão sendo executadas, seguem as normas por entender que são necessárias na organização; é uma geração marcada pelas escolhas, pois preferem estabilidade pessoal e profissional, antes de constituir uma família, por exemplo, e isso não é muito bem interpretado. A pesquisa de campo demonstrou que na geração $\mathrm{X} o$ gênero predominante dos entrevistados é masculino, que o salário é considerado o fator mais importante para motivá-los é que eles conhecem a pesquisa de clima, mas não a veem como importante por não receberem feedback do resultado e não presenciar mudanças necessárias; acreditam que a motivação pessoal e profissional é incentivada sempre pela empresa. Na geração Y, verificou-se que o gênero feminino predomina, a valorização profissional é o fator que consideram importante para motivá-los, conhecem a pesquisa de clima e a consideram como instrumento de melhoria do ambiente de trabalho e acreditam que a motivação pessoal e profissional surge a partir das condições que o colaborador deve buscar externamente. Para as organizações, este estudo poderá servir como orientador de seus processos de gestão de pessoas, uma vez que tem como objetivo propor um fluxograma de aplicação da pesquisa de clima de forma a buscar determinar as etapas de implantação sem que cause impactos nos fatores motivacionais de seus colaboradores das gerações X e Y.

\section{Referências}

ARCHER, Earnest R. O mito da motivação. In BERGAMINI, Cecília W. e CODA, Roberto. Psicodinâmica da vida organizacional: Motivação e Liderança. 2. ed. São Paulo: Atlas, 1997.

BERNARDINHO. Transformando suor em ouro. Rio de Janeiro: Sextante, 2006 .

BISPO, C. A. F. Um novo modelo de pesquisa de clima organizacional. Produção São Paulo, v. 16, p. 258-273, 2006.

BITTENCOURT, Dênia Falcão de. Gestão estratégica de pessoas nas organizações públicas. Palhoça: Unisul Virtual, 2008.

CAMPELlO, M. L. C.; OLIVEIRA, J. S. G. Clima organizacional no desempenho das empresas. Bauru, 2008.
CHIAVENATO, Idalberto Administração de recursos humanos: fundamentos básicos/ Idalberto Chiavenato. 5.ed. São Paulo: Atlas, 2003.

CODA, Roberto. Como está o Clima? In Fascículo n. 15, Programa de Profissionalização do Banco do Brasil. Brasília, 1998.

COELHO, Adriane Mara Rocha. Guerra de gerações: O que aprender com cada um delas?. Acesso em: 04 de mai. 2015, 14:22

DAVIS, Keith; NEWSTROM John. W. Comportamento humano no trabalho. Uma abordagem Psicológica, v.1, São Paulo: Pioneira, 1992.

GRAÇA, H. Clima organizacional: uma abordagem vivencial. Brasília, Fundação Nacional de Desenvolvimento do Ensino Superior Particular FUNADESP, 1999

HERZBERG, Frederick. Mais uma vez: como motivar seus funcionários. In: VROOM, Victor. Gestão de pessoas, não de pessoal. Rio de Janeiro: Campus, 1997.

LOMBARDIA, Pilar García. Quem é a geração Y? HSM Management, n.70, p.1-7. set./out. 2008.

LUZ, Ricardo. Gestão do Clima Organizacional. Rio de Janeiro: Qualitymark, 2006. 350 p.

MARTINS, M.C.F. Clima organizacional. In: SIQUEIRA , M.M.M (org) Medidas do comportamento organizacional: Ferramentas de diagnostico e gestão. Porto Alegre: Artmed, 2008.

ROBBINS, S. P.; JUDGE, T. A.; SOBRAL, F. Comportamento organizacional: teoria e prática no contexto brasileiro. 14. ed. São Paulo: Pearson Prentice Hall, 2010.

SANTOS, Neusa Maria Bastos F. Clima organizacional: pesquisa e diagnóstico. Lorena: Stiliano, 1999.

VIANNA, Marco Aurélio F. Motivação, liderança e lucro: o novo papel do líder. São Paulo: Gente, 1999. 